\title{
Assessment of the Erosion Risk of Sandstorms on Solar Energy Technology at two sites in Morocco
}

\author{
Florian Wiesinger ${ }^{\mathrm{a},}$, Florian Sutter ${ }^{\mathrm{a}}$, Fabian Wolfertstetter ${ }^{\mathrm{a}}$, Natalie \\ Hanrieder ${ }^{\mathrm{a}}$, Aránzazu Fernández-García ${ }^{\mathrm{b}}$, Robert Pitz-Paal ${ }^{\mathrm{c}}$, Martin \\ 5 \\ Schmücker ${ }^{\mathrm{d}}$ \\ ${ }^{a}$ DLR German Aerospace Center, Institute of Solar Research, Plataforma Solar de Almería, \\ Ctra. Senés, km.4, P.O. Box 39, 04200 Tabernas, Almería, Spain \\ ${ }^{b}$ CIEMAT-Plataforma Solar de Almería, Ctra. Senés, km.4, P.O. Box 22, 04200 Tabernas, \\ Almería, Spain \\ ${ }^{c}$ DLR German Aerospace Center, Institute of Solar Research, Linder Höhe, 51147 Cologne, \\ Germany \\ ${ }^{d}$ DLR German Aerospace Center, Institute of Material Research, Linder Höhe, 51147 \\ Cologne, Germany
}

\section{Abstract}

This multi-disciplinary research paper should help solar power plant developers to perform an advanced site assessment in arid locations where the annual irradiance levels are high, but significant quantities of airborne sand and dust increase the risk of optical energy losses due to extinction, soiling, erosion damage (also known as abrasion), etc. Due to these effects sandstorms have a direct consequence on the operation and maintenance (O\&M) costs. The work presented in the following characterizes airborne sand and dust material and later focuses on the resulting erosion effects. Some important meteorological and geological parameters for sandstorm occurrence and the resulting erosive damage on glass materials by impacting windblown material are extracted from literature. The

25 respective parameters have been measured at two locations in Morocco (Zagora and Missour). After evaluation of wind and humidity data and a comprehensive soil analysis, the erosion risk was estimated to be higher in Zagora. The specular reflectance loss of exposed silvered-glass reflectors of $5.9 \%$ in Zagora and $0.8 \%$ in Missour after 25 months of exposure verified this estimation. Additionally, a specular reflectance analysis on a mirror sample that has been exposed for nine months in Kuwait is shown. On that sample specular reflectance losses of more

\footnotetext{
* Corresponding author

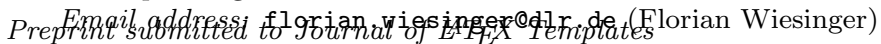


than $40 \%$ were measured. A checklist with seven items is given in the conclusion to help solar plant developers to evaluate the risk of component aging due to sand storm erosion.

35 Keywords: Concentrating Solar Power, Sand Erosion, Site Assessment, Mirror Abrasion, Solar Reflector Aging 


\begin{tabular}{|c|c|c|}
\hline Symbol & Description & Unit \\
\hline$\alpha$ & erosion impact angle & $\circ$ \\
\hline$D_{\text {soil }}$ & mean density of soil & $\mathrm{kg} \mathrm{m}^{-3}$ \\
\hline$N_{i}$ & number of particles in channel $i$ & - \\
\hline$V_{i}$ & mean volume of a particle in channel $i$ & $\mathrm{~m}^{3}$ \\
\hline$V_{a}$ & reference air volume of EDM164 particle counter & $\mathrm{m}^{3}$ \\
\hline$\rho_{\lambda, \varphi}$ & $\begin{array}{l}\text { monochromatic specular reflectance at } \lambda=660 \mathrm{~nm} \text {, } \\
\Theta=15^{\circ} \text { and } \varphi=12.5 \mathrm{mrad}\end{array}$ & $\%$ \\
\hline$\lambda$ & wavelength & $\mathrm{nm}$ \\
\hline$\rho_{\lambda, \varphi, l o s s}$ & loss of monochromatic specular reflectance & $\%$ \\
\hline$v$ & impact velocity & $\mathrm{m} \mathrm{s}^{-1}$ \\
\hline$u_{\tau}$ & friction velocity & $\mathrm{m} \mathrm{s}^{-1}$ \\
\hline$u_{\tau}^{*}$ & threshold friction velocity & $\mathrm{m} \mathrm{s}^{-1}$ \\
\hline$d$ & mean particle diameter & $\mu \mathrm{m}$ \\
\hline$\Theta_{i}$ & radiation incidance angle & $\circ$ \\
\hline$\varphi$ & acceptance half angle & $\operatorname{mrad}$ \\
\hline$E_{g}$ & $\begin{array}{l}\text { gravimetric erosion rate, mass loss of target material } \\
\text { per impacting erodent mass }\end{array}$ & - \\
\hline$E_{p}$ & $\begin{array}{l}\text { particle erosion rate, mass loss of target material per } \\
\text { impacting number of particles }\end{array}$ & $\mathrm{g}$ \\
\hline$E_{C V}$ & erosion classification value & - \\
\hline$K$ or $K_{c}$ & fracture toughness & $\mathrm{MPa} \mathrm{m} \mathrm{m}^{0.5}$ \\
\hline$m_{A}$ & impacting sand mass per reflector area & $\mathrm{g} \mathrm{cm}^{-2}$ \\
\hline$r h$ & relative air humidity & $\%$ \\
\hline$m$ & mass & $\mathrm{g}$ \\
\hline$\Delta m$ & mass loss/gain & $\mathrm{g}$ \\
\hline
\end{tabular}

continued on next page 
Nomenclature

$\begin{array}{lll}\text { Symbol } & \text { Description } & \text { Unit } \\ z & \text { hight above ground } & \mathrm{m} \\ z_{0} & \text { surface roughness length } & \mathrm{m} \\ \kappa & \text { von Kármán constant } & - \\ H & \text { material hardness } & \mathrm{MPa} \\ w & \text { gravimetric soil moisture } & \%\end{array}$

$\begin{array}{ll}\text { Subscript } & \text { Description } \\ p & \text { erodent particle material } \\ t & \text { target material }\end{array}$

\section{Acronyms Description}

$\begin{array}{ll}\text { Acetube } & \text { Accelerated Erosion Tube (for artificial sandstorm aging ex- } \\ & \text { periments) } \\ \text { CSP } & \text { Concentrating Solar Power } \\ \text { CFD } & \text { Computational Fluid Dynamics } \\ \text { EDM164 } & \text { Environmental Dust Monitor } 164 \text { of Grimm } \\ \text { EDX } & \text { Energy Dispersive X-ray Spectroscopy } \\ \text { GHI } & \text { Global Horizontal Irradiance } \\ \text { MENA } & \text { Middle East and North Africa Region } \\ \text { PSD } & \text { Numerical Particle Size Distribution } \\ \text { PV } & \text { Photovoltaic } \\ \text { SEM } & \text { Scanning Electron Microscope } \\ \text { TSP } & \text { Total Suspended Particles }\end{array}$

continued on next page 


$\begin{array}{ll}\text { Acronyms } & \text { Description } \\ \text { DNI } & \text { Direct Normal Irradiance } \\ \text { D\&S } & \text { Devices \& Services Portable Reflectometer } 15 \text {-USB }\end{array}$




\section{Introduction}

Many arid sites in the MENA-region are of high interest for solar energy plant developers because of the high annual irradiation levels. However these

40 regions also lead to high material demands of the used components due to the increased aerosol particle loads in the atmospheric layer close to the ground [1]. Especially the optical energy conversion process is often significantly reduced from its theoretical efficiency due to the presence of sand and dust [2]. On the one hand, this causes soiling on the respective optical surfaces that lowers plant 45 efficiency. Cleaning can reverse the effect but requires manpower and water [3]. On the other hand, an increased presence of aeolian particles also leads to optical scattering and absorption processes in the air between the different optical components of solar power plants. This phenomenon is known as atmospheric extinction and is of special importance for central receiver concentrating solar power plants, where the spatial distance between the reflecting heliostats and the absorber can be up to several kilometers [4. A third effect are windblown aerosol particles, which may cause possible mechanical damage when impacting on the optical components. All of the three effects lead to optical performance losses which decrease the economic benefit of a solar energy power plant. For 55 a 50 MW concentrating solar power plant (CSP) located in Spain an annual financial loss of $0.7 \mathrm{M} €$ could be calculated when the reflectance of the mirrors is decreased by $1 \%$. 5 . Therefore there is a strong interest of the CSP and also photovoltaic (PV) industry to develop testing procedures which are capable to estimate the lifetime of optical components as it was recently done by many groups [6, 7, 8, 9, 10, 11.

The present work concentrates on the permanent mechanical damage by windblown particles causing surface abrasion (hereafter referred to as "erosion"). It was widely studied in literature on many different materials and with a variety of input parameters [12, 13, 14. In this study, the defects in glass reflectors provoked by air-borne particles at two representative sites in Morocco (Zagora and Missour) are analyzed. Because glass, with technology-appropriate surface 
coatings, is the state of the art material to maintain high efficiency of CSP as well as PV systems, the findings of the present work are relevant for both technologies [15, 6]. Depending on the respective site differences a measurable optical performance loss could be detected. A comprehensive outdoor study undertaken by Wette et al. [16] who exposed samples on seven outdoor sites, found massive erosion defects only in Zagora. In addition to the Moroccan sites, an outdoor exposure campaign undertaken by the company TSK (Gijón, Spain) of glass reflectors in Kuwait is presented. They also show a significant performance loss due to the presence of sandstorms.Their finding is consistent with the extensive literature addressing the severe sandstorm activity in the Kuwait region [17].

Within this work, the erosion determining factors are discussed, the critical sand movement principle is explained and resulting data from the investigated outdoor sites are shown. The differences between the varying reflectance losses at the distinct sites can be mainly explained by the particle size distribution of the soil, the mineralogical composition of the soil, the wind velocity in combination with relative humidity, the prevailing wind direction with respect to the solar collector orientation, and the characteristics of the local landscape.

\subsection{Defects on brittle materials}

From the mechanical point of view, glass can be classified as a brittle material which forms erosion pits and cracks when exposed to harsh solid particle impacts. It has been shown in literature that defects caused by sandstorms on various construction materials is as real as on exposed glass samples for solar energy applications [18] [10]. Within the present work, further evidence from a field exposure in Morocco and Kuwait will be given as well in order to emphasize the actuality of the issue of glass erosion. This is due to the low fracture toughness $K$ (or critical stress intensity factor, sometimes also labeled $K_{c}$ ) of glass. Depending on $K$ the overall erosion process of a material can be described as ductile or brittle, respectively. Brittle materials will suffer from material loss due to splitting effects while ductile erosion can be characterized 
by a cutting and ploughing process exerted by the erodent (i.e. the abrasive or eroding material) on the target material. The difference between both regimes is very well depicted by the dependency of the impact angle $\alpha$ on the erosion rate $E_{g}$ (material loss per impacting mass). Wensink and Elwenspoek [19] defined an "erosion classification value" $E_{C V}$ as the ratio of $E_{g}$ at $\alpha=45^{\circ}$ to $E_{g}$ at $\alpha=90^{\circ}$. For $E_{C V}>1$, the erosion process is classified to be ductile while $E_{C V}$ values for brittle materials are typically around 0.45 . Apart from $\alpha$, the erosion mechanisms on brittle materials are depending on the impact velocity, on mass and shape of the erosive particles, on the mechanical properties of the erodent and target material and to a certain extent on the environmental conditions. The erosion regime is not inherent to a certain material combination but transitions between the ductile and the brittle regime can occur depending on the erosion parameters. A study undertaken by Sheldon and Finnie [20] demonstrates that nominally brittle materials can show ductile behavior when erodent particle size and impact velocity are within certain limits. The multi-parameter dependencies of erosion processes can become quite complex but are in general well represented in so called erosion maps (see two examples in Fig. 1).

Depending on the particle and target characteristics, there is a certain threshold of kinetic energy for elastic impacts. The erodent as well as the target, will not be altered by those impacts and no damage is caused. Above that critical energy, the impact is inelastic and several different crack types can be the consequence. The transition from elastic to inelastic is not abrupt, especially for erosion with non homogeneous erodents, all different types of cracks can be found on the target. The state of the target surface is a further critical factor governing the defect formation. In the case of a silica glass target, strong covalent $\mathrm{Si}-\mathrm{O}$ bonds would result in a theoretical strength of $\approx 17 \mathrm{GPa}$ but the practical yield strength is often found in the range of only 50-150 MPa. This is because of flaws, scratches, bubbles and inclusions [21].

125

Most scientific literature describe the erosion rate $E_{g}$ with the help of the relative weight loss. This relative weight loss is defined as the amount of mass of 

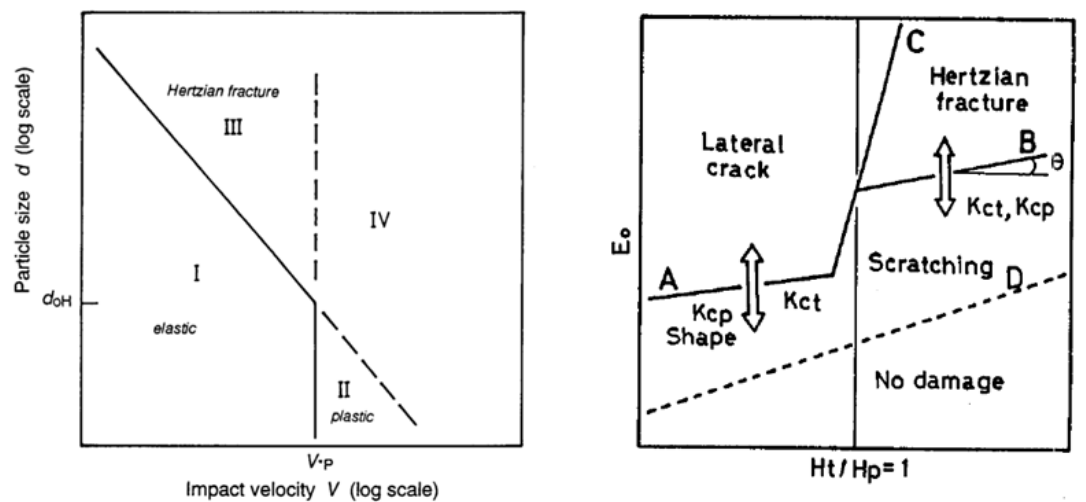

Fig. 1: Two examples of erosion maps of brittle materials: Hutchings [12] (left) points out four regimes of erosion in dependence on the impact velocity and the particle size. Wada [13] (right) describes four different regimes by combining particle size and the impact velocity to the impact energy $E_{0}$ on the y-axis and the ratio of the hardnesses on the x-axis. The indices $p$ or $t$ stand for particle and target, respectively.

the target material removed by a unit mass of erodent material $\left[\Delta m_{t} / m_{\text {erodent }}\right]$, or sometimes as $E_{p}$ standing for $\Delta m_{t}$ per erodent particle. The results obtained by this parametrization is applicable only to a certain extent to the loss of optical performance. A glass mirror may lose a significant part of its specular reflectance $\rho_{\lambda, \varphi}$ without any detectable mass loss due to scratches or cracks. However the fundamental relations between the erosion determining parameters and $E_{g}$ might help to find a valid correlation to $\rho_{\lambda, \varphi}$ as well, at least in a region that sufficiently covers the objectives of this work.

In a previous study, Feng and Ball [14] tested four target materials with seven different erodents and varied the impact velocity $v$, the erodent diameter $d$ and the impact angle $\alpha$. For a glass target in the investigated range of impact velocity ( $v$ between 33 and $99 \mathrm{~m} \mathrm{~s}^{-1}$ ), they found an increase of $E_{p}$ with $v^{2}$ for angularly shaped particles. Furthermore it could be demonstrated that the exponent over $d$ is around four. For erodents of similar density and size, $E_{p}$ increases with increasing ratio of erodent particle- to target hardness $\left(H_{p}\right.$ and $H_{t}$, respectively), because of the enhanced ability to penetrate into the 
target material without fragmentation of the erodent. These results could be summarized as:

$$
E_{p} \propto v^{2.37} d^{4}\left(H_{p} / H_{t}\right)^{0.47}
$$

Wada [13] also states that $E_{g}$ is proportional to $d^{m}$ and $v^{l}$ with varying parameters $m, l$. They investigated especially the effects of $H_{p} / H_{t}$ on $E_{g}$. They concluded that $E_{g}$ is proportional to $\left(H_{p} / H_{t}\right)^{a}$. For $H_{p} / H_{t}$ smaller than 1 the erosion mechanism is mainly based on scratching and otherwise on fracture. If fracture is the dominant process, then $E_{g} \propto K_{t}^{b}$ where $b$ is a negative number. Also $K_{p}$ affects $E_{g}$ in a proportional manner. Accordingly, the erosion map in Fig. 1(right) was developed.

It needs to be stated as well, that a lot of threshold effects for $E_{p}$ were demonstrated regarding the effects of increasing $d$ for a spherical particle [14]. Below a certain value of $d$ no defects might be caused by the impacting particles and only after exceeding a critical threshold, measurable defects become obvious. Furthermore Buijs and Pasmans 22] recognized a critical transition of the exponent of the impact velocity dependence on erosion rate. At lower impact velocities, it was argued that the force imparted to the glass surface during maximum penetration is lower than the threshold for fracture of glass and the erosion rate is mostly governed by scratching. Relationships between the erosion rate and the influencing parameters are therefore not constant over the whole range of parameter values.

So far, only glass as target material was addressed, but actually most PV modules are produced with a further anti-reflective coating on top of the glass substrate. Due to their lower hardness, these coatings are more susceptible to erosion effects [23 and an outdoor exposure of these distinct coatings would be necessary to arrive at detailed predictions on specific lifetime expectations. A comparative study among different anti-reflective coatings after a laboratory erosion treatment is dealing with this issue 24 in more detail. 


\subsection{Saltation movement}

The movement of sand particles over a surface can be subdivided into three classes: Reptation, saltation and suspension [25, 26. The diameter borders separating the respective classes should be understood as approximate measures, since they are defined differently among the cited publications. Particles which are smaller in diameter than $50 \mu \mathrm{m}$ become suspended in the air and can be transported over distances larger than $1000 \mathrm{~km}$ [27]. However due to their small size, it can be assumed that they mostly do not provide sufficient kinetic energy to cause damage on typical solar energy materials like PV-Panels or glass mirror reflectors for CSP applications 28]. The diameter of particles involved in reptation (also known as surface creeping) is of the order of millimeters. Grains of this size are not lifted up in the air but perform a diffusive vibrating motion on the ground which leads to surface transport. Bagnold [25] states that the contribution of creeping to the total mass flux is between a quarter and a fifth. Particles which are in between these two diameter limits are able to take part in the saltation process. Local wind turbulences lift particles up from the surface in the air stream where they become accelerated. When those grains impact the soil surface again, yet more grains can be ejected into the wind and the saltation maintains itself (avalanche effect) until a saturated sand flux is established [27. Also the grains in surface creep receive their momentum from impacts of saltating particles.

Typically the bulk part of saltation is transported in close distance to the ground [25] but there is also evidence that grains of $3-4 \mathrm{~mm}$ attain heights of more than $3 \mathrm{~m}$ [29]. Thornton [30] found $2 \mathrm{~mm}$ grains at $6 \mathrm{~m}$ above ground and Sansom et al. 31] could detect particles of around $0.8 \mathrm{~mm}$ at $2 \mathrm{~m}$ above ground in Libya. After a field study on a gobi site in western China, Cheng et al. 32. could conclude that the typical upper limit for windborne sand matter of $2 \mathrm{~m}$ can be shifted up to 3 or $4 \mathrm{~m}$ at gobi sites. They could detect particles with diameters of $3-5 \mathrm{~mm}$ at those heights above ground. However it should be stated that the measured wind velocities of $41 \mathrm{~m} \mathrm{~s}^{-1}$ (at $10 \mathrm{~m}$ height above ground over an open space with no obstacles) are quite high. 


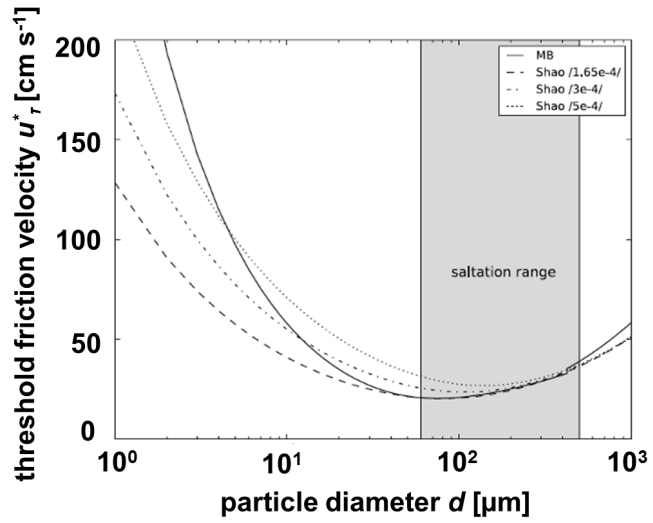

Fig. 2: $u_{\tau}^{*}$ over a smooth surface calculated after different dust emission schemes (taken from [33].

A certain fluid drag is necessary in order to bring the first particles from the surface into saltation mode, which is caused by the threshold friction velocity $u_{\tau}^{*}$. For most natural sands Nickling 34] suggests that this threshold should not be defined by a finite value but as a range of $u_{\tau}^{*}$. Models can be employed to estimate the $u_{\tau}^{*}$ as it was done by Darmenova et al. 33. Fig. 2 shows their results for different assumptions. These calculations were done for a parent bed of similar, equally sized and uniform soil particles only. This assumption is barely fulfilled for natural systems. Nevertheless, it points to the critical effects that promote or impede saltation. On the left side of the indicated saltation region (gray area), where the particle diameter is smaller than $60 \mu \mathrm{m}$ the increasing inter-particle cohesive forces impede saltation as well as the prevalent dominance of the gravity force does for particles which are larger than $500 \mu \mathrm{m}$. A minimum for $u_{\tau}^{*}$ is found for $d$ between 65 and $200 \mu \mathrm{m}$. Also the Bagnold and the Greeley-Iverson schemes [25, 35] predict a minimum $u_{\tau}^{*}$ for individual particles at the size of around $80 \mu \mathrm{m}$. The study by Mikami et al. 36] ascribed the higher saltation fluxes at a Gobi site in comparison to a collocated dune site to the maximum in the particle size distribution (PSD) which was at 80 and $200 \mu \mathrm{m}$ for the gobi and the dune site, respectively. In practice, $u_{\tau}$ can be 
determined by taking into account the logarithmic law of the wall 37 .

$$
u(z)=\frac{u_{\tau}}{\kappa} \ln \left(\frac{z}{z_{0}}\right)
$$

and measuring the wind speed at various heights $z$. Eq. 2 can then be applied to obtain $u_{\tau}$ and $z_{0}$. Here $\kappa$ is the von Kármán constant $(\approx 0.4)$. The parameter $z_{0}$ is called the roughness length of a certain terrain and depends on the topography, the height and the distribution of roughness elements on the investigated surface.

A comprehensive wind tunnel investigation on the effects of $u_{\tau}$, PSD and particle shape on the saltating particles was published by Williams [38. The effect of $u_{\tau}$ on the mean size of saltating particles was very small at the investigated distance above ground. A higher grain sphericity of the soil particles increases the height where particles with a given diameter are expected to be present. The rate of particle movement was investigated and an exponential power law was found as the basic relation between transport mass and height above ground. This finding was later confirmed in a field study by Farell et al. 39 who also measured a vertical mass flux profile showing an exponential decay.

Willetts et al. 40 further showed that the particle shape has a pronounced effect on saltation because considerably higher material transport rates were observed for sandbeds containing particles of high sphericity. Segregation of soil particles by various transport rates was found to be of minor influence unless the soil consists of size fractions smaller than $50 \mu \mathrm{m}$, where sorting can be a critical factor for transport rates. Another study by Willetts 41 could further show that lower grain sphericity exhibits higher transport rates at low wind velocities $\left(u_{\tau}<0.5 \mathrm{~m} \mathrm{~s}^{-1}\right)$ but a lower rate at high wind velocities. They observed a transition in transport rates for spherical grains as a result of a shift in regime from wind dislodgement to collision dislodgement. An experimental study by Nickling [34] used sand of different mean diameters, sorting characteristics and particle shapes. In contrast to [38, 40, 41] he concluded that the particle shape is of much less importance in controlling $u_{\tau}^{*}$ than the particle size. Interestingly the testing with bimodal size distributions by Nickling [34] showed 
180

argued that the rapid increase might result from the preferential entrainment of particles from the finer mode of grain sizes, at relatively low friction velocities, which then in turn dislodge a large number of other stationary surface grains of larger modes. Furthermore, differences in surface packing -as it is caused by bimodal distributions- lead to particles being more exposed to wind stress and consequently are more susceptible to entrainment at lower wind speeds.

Apart from the aforementioned parameters, the gravimetric soil moisture $w$ is used as a critical input parameter for many dust emission models, since it is well known that it strongly contributes through adhesion and capillary effects to the binding forces keeping particles together [42]. Changes of the atmospheric relative humidity $(r h)$ contribute to most of the variability of $w$ in arid regions [43]. The soil moisture can be related to the clay content [44 which is known to influence the adsorption capacity of the soil. Hence, soils with a higher clay content can be ascribed a higher $u_{\tau}^{*}$ than sandy soils when humidity is present. increasing $w$ for low moisture contents until a certain value of $w$ where a steep increase of $u_{\tau}^{*}$ becomes apparent. $u_{\tau}^{*}$ reaches values where no saltation can take place anymore and the critical moisture content is defined at that point. These results are in line with the wind tunnel experiments on wet and dry sands conducted by Selah and Fryrear [46]. Darmenova et al. [33] presents an in-depth analysis of two physically based dust emission schemes and reports a strong dependency of $u_{\tau}^{*}$ on $w$. 


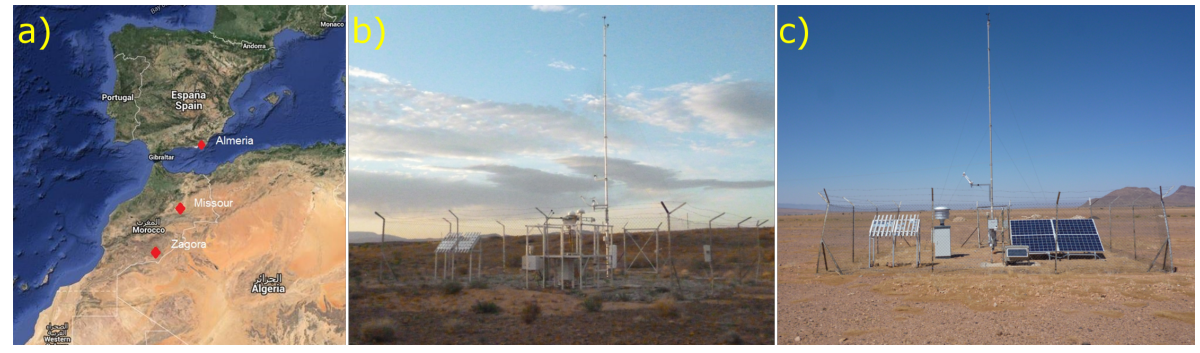

Fig. 3: Illustration of outdoor exposure sites in Morocco: a) site locations; b) Missour meteo station and c) Zagora meteo station.

\section{Methodology}

\subsection{Outdoor data acquisition}

For this study, results from a 25 month (1 April 2015 - 1 May 2017) outdoor

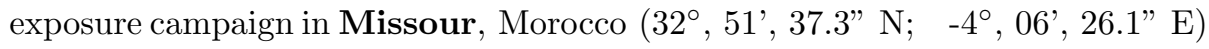
and Zagora, Morocco $\left(30^{\circ}, 16^{\prime}, 19.8^{\prime \prime} \mathrm{N} ;-^{\circ}, 51^{\prime}, 5.8^{\prime \prime} \mathrm{E}\right)$ are used. Their respective position is indicated on the map in Fig. 3(a). The two stations belong to the enerMENA meteorological network [47, 48. Both site locations can be described as arid zones with poor vegetation. An overview for the general meteorological data during the 25 month period is given in Table1. Only data points which were present at both sites at the specific time were used for evaluation. This led to a total number of 849,000 data points with 1-minute temporal resolution. Both sites exhibit high irradiation values and the $G H I$ as well as the DNI makes the sites suitable for PV or CSP applications. Higher average temperature and lower average relative humidity indicate the more desertic nature of the Zagora site compared to Missour. In order to characterize the sand particles present at the sites, soil samples were manually taken from the topsoil layer. They were analyzed by optical and electron microscopy and X-ray diffraction to determine numerical size distribution $\left(\mathrm{PSD}_{\text {num }}\right.$ which displays the number of particles with a certain diameter), shape characteristics and mineralogical composition. In order to monitor aeolian particles, the EDM164 particle counter manufactured by GRIMM Aerosol Technik GmbH\&Co.KG was mounted at a 


\begin{tabular}{|c|c|c|c|c|c|c|}
\hline & \multirow{2}{*}{\multicolumn{2}{|c|}{$\begin{array}{c}\text { temperature } \\
\qquad\left[{ }^{\circ} \mathrm{C}\right]\end{array}$}} & \multirow{2}{*}{$\begin{array}{c}\text { wind speed } \\
\qquad \text { (gusts) } \\
{\left[\mathrm{m} \mathrm{s}^{-1}\right]}\end{array}$} & \multirow{2}{*}{$\begin{array}{c}\text { relative } \\
\text { humidity } \\
{[\%]}\end{array}$} & $G H I$ & $D N I$ \\
\hline & & & & & \multicolumn{2}{|c|}{$\left[\mathrm{kWh} \mathrm{m}^{-2} \mathrm{a}^{-1}\right]$} \\
\hline \multirow{3}{*}{ Zagora } & Average & 24.2 & 4.2 & 25.3 & 2172 & 2328 \\
\hline & Min & -1.9 & 0 & 0 & - & - \\
\hline & Max & 47 & 25.1 & 96.4 & - & - \\
\hline \multirow{3}{*}{ Missour } & Average & 19.2 & 3.8 & 47.7 & 2070 & 2307 \\
\hline & Min & -3.6 & 0 & 2.6 & - & - \\
\hline & $\operatorname{Max}$ & 43.1 & 29.2 & 100 & - & - \\
\hline
\end{tabular}

Table 1: Meteorological data from outdoor sites Missour and Zagora, Morocco, between April 2015 and May 2017 (Irradiation data between June 2013 and June 2015 from Schüler et al. 47]). The direct normal irradiance (DNI) is measured with a rotating shadow band irradiometer (type: RSP-4G) in Zagora. In Missour, a solar tracker with mounted CHP1 pyrheliometer by Kipp \& Zonen is installed. Temperature and relative humidity are measured by a Campbell Scientific CS100 and the wind velocity and direction at $10 \mathrm{~m}$ height is measured with a \#40C and a \#200P from NRG, respectively.

sampling height of around $1 \mathrm{~m}$. Data from this instrument are only available in the second half of the field campaign and are evaluated from April 2016 to May 2017. The EDM164 counts airborne particles with diameters ranging from 0.25 to $1200 \mu \mathrm{m}$ by light scattering optics. It differentiates between 31 size channels where the largest channel samples all particles with diameters larger than $32 \mu \mathrm{m}$. It has to be noted that the EDM164 has a certain sampling efficiency which is not uniform for different particle sizes [4. Especially larger particles are sampled only to a certain extent. The evaluation will therefore only be performed up to particle diameters of $31 \mu \mathrm{m}$ in order not to lose accuracy. From the count rates $N_{i}$ in the different size channels $i$, the total suspended particle mass $(T S P)$ can be calculated after Eq. 3

$$
T S P(t)=\sum_{i=1}^{30} N_{i}(t) \cdot V_{i} \cdot D_{\text {soil }} / V_{a},
$$



Axio CSM 700 microscope (Zeiss). For the soil sample analysis, ImageJ processing software was used. The micrographs were converted into binary pictures after a background noise subtraction and color threshold adjustment. Thereby it was possible to draw conclusions about the size and the shape of single par230 was measured with a portable specular reflectometer 15-USB by Devices and Services (herein referred to as D\&S). Furthermore a scanning electron microscope (SEM) Gemini Ultra 55, manufactured by Zeiss, with an INCA FETx3 Energy Dispersive X-ray spectroscopy module (EDX) was used to determine 


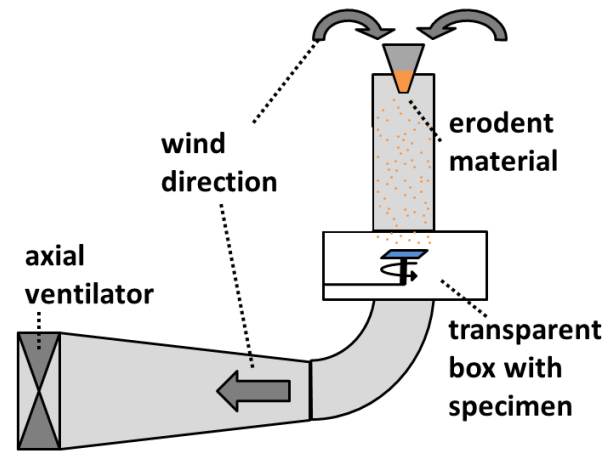

Fig. 4: Operating principle of the accelerated erosion simulation tube (Acetube) constructed at the PSA.

the elemental composition. In order to conduct accelerated erosion simulation processes, an open loop wind tunnel with particle injection -named Acetubewas constructed at the PSA [51. A sketch of its working principle is given in Fig. 4 It is equipped with an Axial Ventilator Type AXN 12/56/400 M-D by TROX TLD which is used in suction mode. Erodent material can be applied from above via different methods, depending on the erodent properties (coarse or fine). The specimen to be tested is mounted on a rotating plate in the transparent box in order to establish a homogeneous defect distribution over the specimen surface [52. The impact angle $\alpha$ is fixed at $45^{\circ}$ for the present investigation. Wind velocities were determined at the specimen position during a calibration process in reference to the ventilator power by the application of an ultrasonic wind sensor from FT technologies LTD. The natural soil from Zagora and Missour was used as erodent material with all particles larger than $150 \mu \mathrm{m}$ being removed. This limit was chosen on the one hand because of the initially mentioned size limit for saltating particles and on the other hand because of the availability of adequate meshes. The total erodent mass applied at each tested wind velocity was $60 \mathrm{~g}$ which leads to an impacting sand mass per reflector area of $m_{A}=0.19 \mathrm{~g} \mathrm{~cm}^{-2}$, which can be calculated using the tube diameter of $20 \mathrm{~cm}$. 


\section{Results and Discussion}

\section{3.1. Meteorological measurements}

The average wind velocity $u$ in Zagora is higher than in Missour and mean $r h$ is about twice as high in Missour as in Zagora (see Tab. 1). Both parameters play an important role for potential sand movement. Therefore a more complete analysis of $u$ and $r h$ was performed and is shown in Fig. 5p. The histogram shows the frequency of certain events. It can be seen that the probability of strong wind events with velocity of $8-16 \mathrm{~m} \mathrm{~s}^{-1}$ is more pronounced in Zagora in comparison to Missour. However the extreme wind events from 16 up to $29 \mathrm{~m} \mathrm{~s}^{-1}$ are more frequent in Missour. Fig. 5(b) shows the frequency of relative humidity in 5\% intervals. Very dry periods with $r h$ lower than $10 \%$ are around seven-times more frequent in Zagora than in Missour. Since these $r h$ levels are supposed to be of special importance for saltation processes, the absolute hours of the respective $u$-bins have been evaluated in Fig. 5(c). The total hours of extreme wind events $\left(u>16 \mathrm{~m} \mathrm{~s}^{-1}\right)$ in Zagora is around 4 times larger than in Missour when only $r h<10 \%$-periods are taken into account. For strong winds $\left(8-16 \mathrm{~m} \mathrm{~s}^{-1}\right)$ this factor is about 5 . This combination of low relative humidity and high wind velocity promotes the probability of saltation [53, 54]. It can be concluded that the independent examination of the parameters $r h$ and $u$ from Fig. 5(a) and (b) or the annual averaging as it has been done in Tab. 1 cannot lead to the same conclusion about potential saltation processes. 275 A more thorough evaluation is necessary in order to perform a meaningful site assessment for the estimation of sandstorm threats to solar power plants.

In order to describe the aeolian dust concentration, the $T S P$ data measured by the EDM164 is plotted in Fig. 6 for a typical week for both sites. It can be seen that the TSP values of Zagora are higher than in Missour and they generally lay below $1000 \mu \mathrm{g} \mathrm{m}^{-3}$. However, for both sites, TSP considerably exceeded the limit during several events. The highest measured TSP values were 716,760 and 41,903 $\mu \mathrm{g} \mathrm{m} \mathrm{m}^{-3}$ for Zagora and Missour, respectively. The World Meteorological Organization (WMO) [55] defines a sandstorm based on 

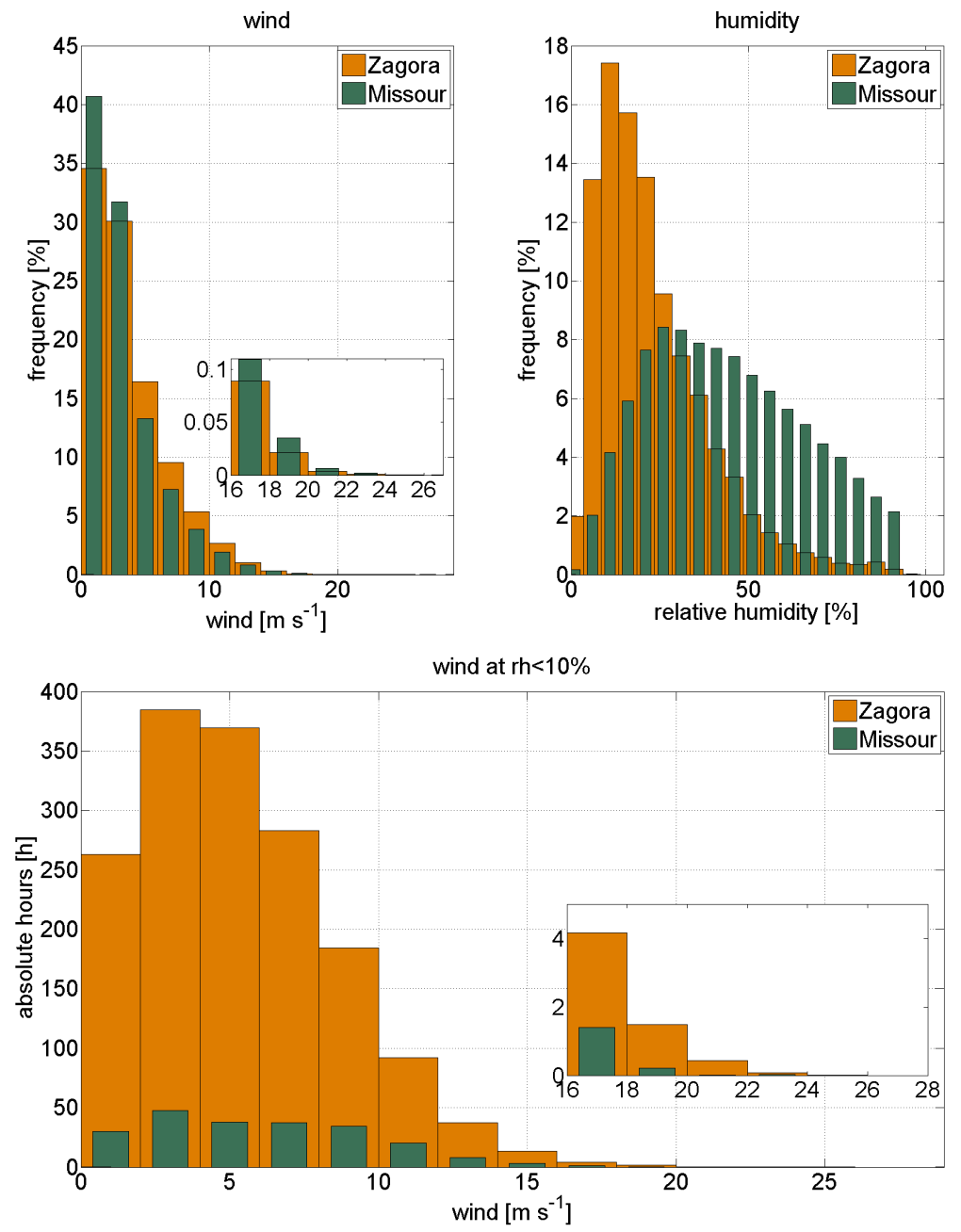

Fig. 5: Relative frequency of a) wind- and b) humidity ranges for the time period between April 2015 and May 2017 and a temporal resolution of 1 minute; c) Absolute frequency of wind events where relative humidity values are below $10 \%$. 


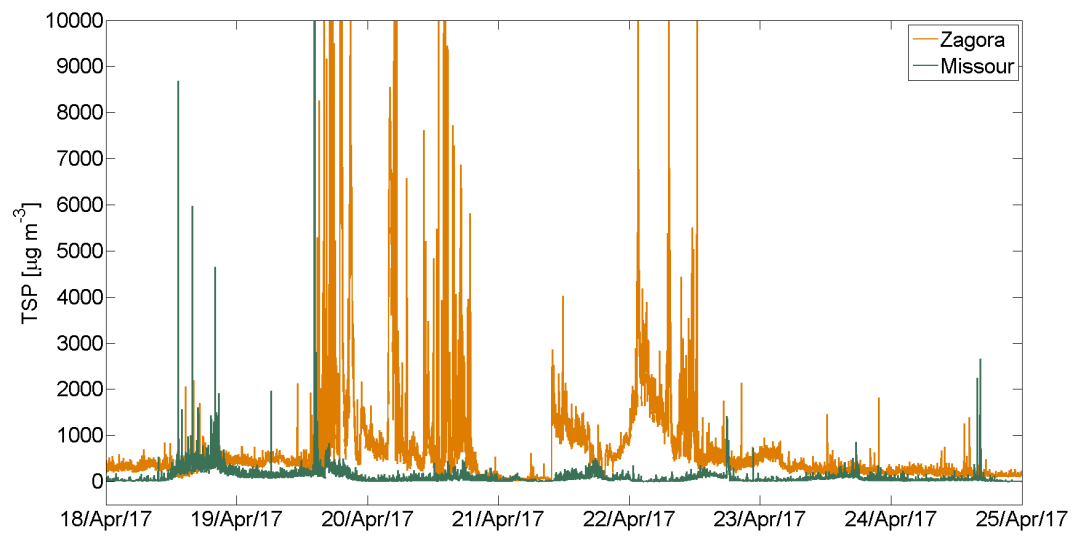

Fig. 6: TSP values from the EDM164 particle counter for one week in April 2017.

the horizontal visibility which is related to current TSP [56]. No clear threshold

limit for $T S P$ is defined for sandstorm classification but from Subramaniam et al. 17] and Kandler et al. [57] a value of $1000 \mu \mathrm{g} \mathrm{m} \mathrm{m}^{-3}$ seems reasonable. Counting the data points above $1000 \mu \mathrm{g} \mathrm{m}^{-3}$ during the present field campaign leads to 131.2 and 17.7 hours (in the timeframe 1.April 2016 until 1.May 2017) for Zagora and Missour, respectively. Therefore it can be concluded that the meteorological and geological conditions in Zagora favor the movement of aeolian material in comparison to Missour.

\subsection{Soil analysis}

A scanning electron microscope (SEM) image of the soil samples taken from Zagora and Missour is shown in Fig. 7. It can be seen that the main volumetric contribution in Zagora comes from particles larger than $100 \mu \mathrm{m}$ while in Missour many smaller particles are present as well. The soil appears more loam-rich and with a lot of silt and clay particles. The optical microscope analysis of soil samples from Zagora and Missour reveals the $\mathrm{PSD}_{\text {num }}$ as shown in Fig. 8 Before the analysis, all particles with diameters larger than $425 \mu \mathrm{m}$ have been removed by sieving. Around 50,000 particles in that size range have been measured and their respective quantity sorted in $10 \mu \mathrm{m}$-size bins. The relative percentage of 

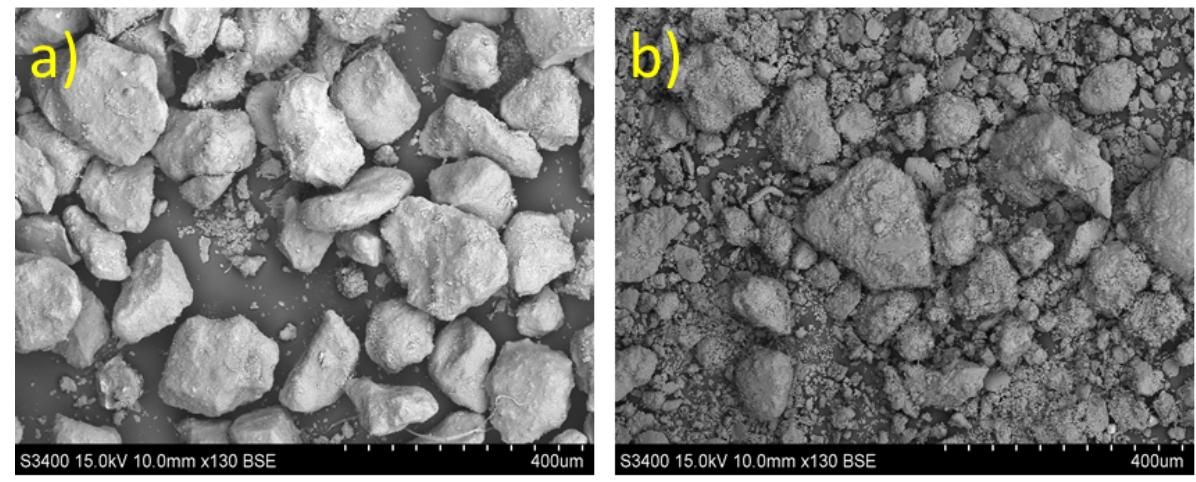

Fig. 7: SEM picture of soil sample taken from Zagora (a) and Missour (b).

the particle numbers in Missour is decreasing more or less monotonously on the logarithmic scale with increasing particle diameters and no particles with diameters larger than $200 \mu \mathrm{m}$ could be detected. The $\mathrm{PSD}_{\text {num }}$ of Zagora also decreases for the small- and the large size bins, but in the region between 35 and $130 \mu \mathrm{m}$ another mode is present. The largest particle detected in the prepared soil sample of Zagora had a diameter of around $375 \mu \mathrm{m}$. Assuming spherical particles and material densities from the results of the mineralogical composition evaluation, the $\mathrm{PSD}_{\text {num }}$ from the optical image procedure could be converted into a gravimetrical size distribution which could be compared with the results of a sieve analysis. The functionality of the applied optical procedure could be verified. Furthermore the mechanical sieving exhibited mass ratios of particles smaller than $32 \mu \mathrm{m}$ (corresponding to medium, fine and very fine silt and clay minerals after the Wentworth scale) of 7.4 and $0.3 \%$ in Missour and Zagora soil, 315 respectively.

As it has been pointed out before, there is a minimum of the threshold friction velocity $u_{\tau}^{*}$ for particles with diameters between 65 and $200 \mu \mathrm{m}$ (see Fig. 2 and the second mode of the $\mathrm{PSD}_{\text {num }}$ of Zagora lies in that size range. The presence of this second mode and its overlap with the minimum of the $u_{\tau}^{*}$ favors the onset of saltation in Zagora. For Missour, particles at that specific size range are present as well but because of their smaller contribution to the 


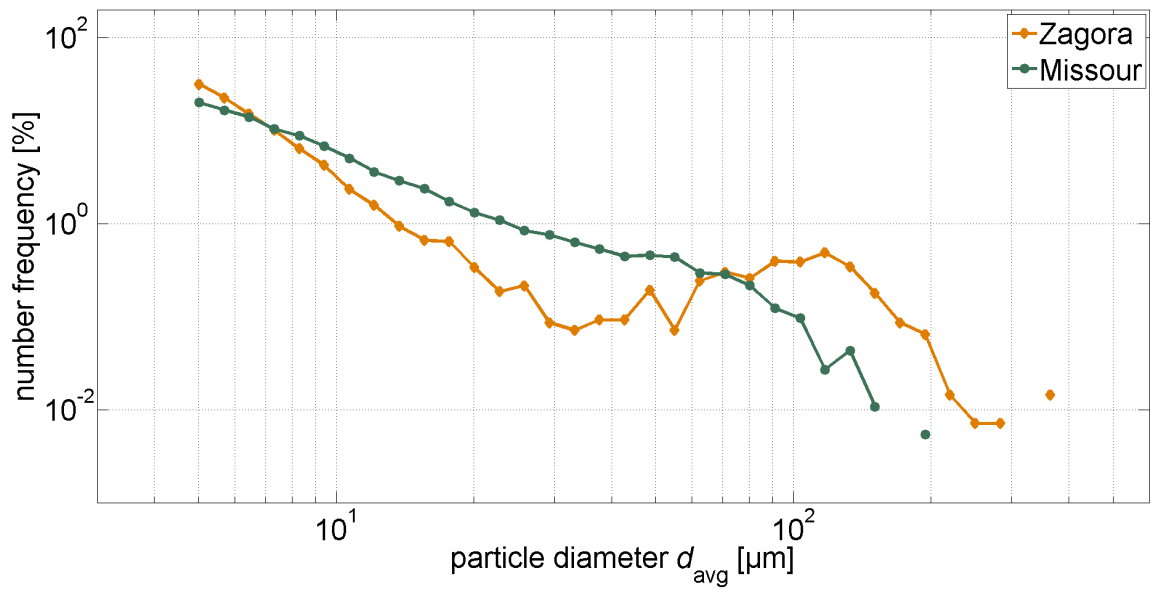

Fig. 8: $\mathrm{PSD}_{\text {num }}$ of the soil fraction $<425 \mu \mathrm{m}$ from Missour and Zagora evaluated by an optical imaging procedure.

complete $\mathrm{PSD}_{\text {num }}$ they are less exposed and their ejection from the sandbed into saltation mode is suppressed.

Elemental analysis and conversion to the most prominent oxide compounds lead to the mineralogical composition in Table 2. The major constituent of the soil in Zagora is quartz, with a content of $73 \mathrm{wt} . \%$, followed by some minor percentages of clay- and carbonate minerals. The situation is completely different for the soil from Missour where quartz is only contributing around 13wt.\% to the total mass. More than two thirds of the soil in Missour are carbonate minerals and around 14wt.\% of gypsum could be identified.

On the one hand, the high clay content leads to an augmented water adsorption capacity. Therefore a higher mean soil moisture is expected 44 which impedes saltation in Missour. A simple experiment was conducted to provide further evidence on the increased water adsorption potential of the soil from Missour compared to Zagora. Therefore a small sample of both soils was exposed overnight outdoor at the PSA at a relative humidity of around $50 \%$. In the morning the samples were weighed and then heated up to $100^{\circ} \mathrm{C}$ for two hours to remove adsorbed water. Immediately afterwards, the samples were weighed again and the relative mass loss could be derived. In case of Zagora the loss was 

in favor of an elevated risk of erosive sandstorm events at the Zagora site in comparison to Missour.

\begin{tabular}{ccccccccc}
\hline & $\mathrm{Na}_{2} \mathrm{O}$ & $\mathrm{K}_{2} \mathrm{O}$ & $\mathrm{MgO}$ & $\mathrm{Al}_{2} \mathrm{O}_{3}$ & $\mathrm{SiO}_{2}$ & $\mathrm{CaO}$ & $\mathrm{Fe}_{2} \mathrm{O}_{3}$ & $\mathrm{SO}_{2}$ \\
\hline Zagora & 1 & 3 & 1 & 8 & 73 & 8 & 5 & 1 \\
Missour & 1 & 1 & - & 4 & 13 & 67 & - & 14 \\
\hline
\end{tabular}

Table 2: Results from EDX-analysis of soil samples taken at the different sites given as mass fraction [wt.\%].

Regarding the shape of particles, the common definitions after Krumbein and Sloss [59] will be used in the following. The two basic parameters, the sphericity (in contrast to ellipticity is describing the volume ratio of the actual partical to that of a circumscribing sphere) and the roundness(in contrast to angularity is describing how smooth a grain is) were evaluated from the soil at the respective sites and are shown in Fig. 9. Only particles with diameters larger than $20 \mu \mathrm{m}$ were taken into account since they are supposed to contribute the most to the saltation and moreover are responsible for the mechanical defects on the reflector surface. The circularity as well as the roundness behave similar at both sites and no conclusion towards an augmented erosion or saltation behavior can be drawn from the data. However, it can be stated that the effectively 

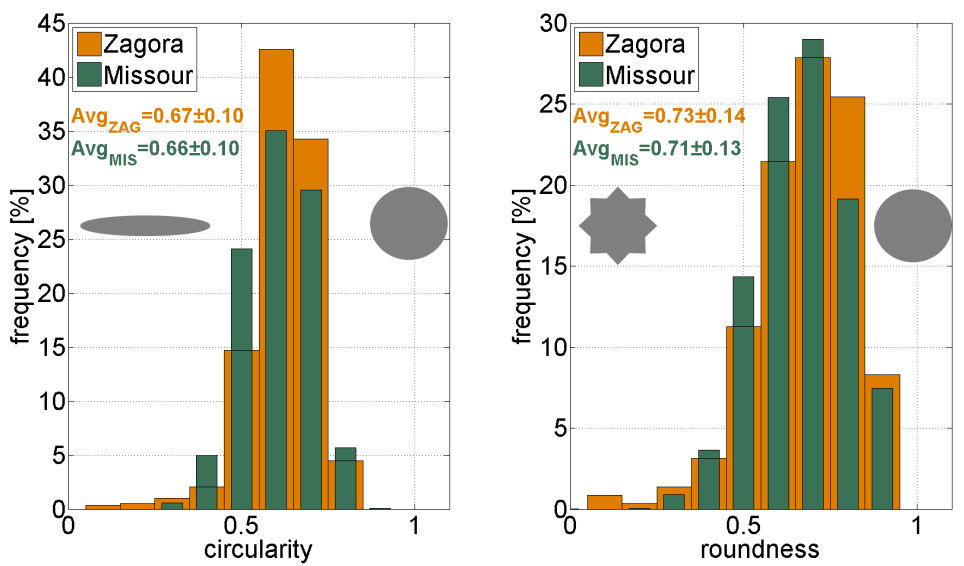

Fig. 9: Shape analysis of soil particles of Zagora and Missour with evaluation of the circularity (a) and the roundness (b). The symbols in gray illustrate graphically the meaning of the two parameters. Only particles larger than $20 \mu \mathrm{m}$ were analysed. Mean value and respective standard deviation are given.

higher erosion potential which is present in Zagora is not caused by a significant difference of the particle shape of the sand particles at that site.

\subsection{Solar reflector erosion}

In order to accurately assess the potential risk of erosion due to sandstorms, an exposure of representative material is essential. Virgin glass samples in their as-received state from the manufacturer were used for the outdoor exposure campaign. No initial defects were detected after an optical microscope investigation. The two glass reflector samples shown in Fig. 10 were exposed in Zagora (a) and (c) and in Missour (b) and (d) for 25 months. In Zagora the erosive environmental conditions caused a variety of defects on the surface. It exhibits a high density of plastically deformed spots with typical dimensions of only a few $\mu \mathrm{m}$. In Fig. 10(c), which is the magnification of the yellow box in (a), one of the larger plastically deformed spots is displayed which measures around $60 \mu \mathrm{m}$. Alongside of the shallow surface scratches, lateral cracks with diameters of up to $300 \mu \mathrm{m}$ and depths of around $50 \mu \mathrm{m}$ can be observed as well. For Missour the defect picture of the glass surface is less prominent. Only a few 

spots are present nor does fracture occur. The damages caused by the environmental conditions at the exposed solar reflectors can be quantified by measuring the specular reflectance $\rho_{\lambda, \varphi}$. For Zagora $\rho_{\lambda, \varphi}$ decreased by $5.9 \pm 0.4 \%$ from an initial value of $96.3 \pm 0.0 \%$ to $90.4 \pm 0.4 \%$. In Missour this loss of $\rho_{\lambda, \varphi}$ was only exposure respectively. Not all the loss of $\rho_{\lambda, \varphi}$ is necessarily the result of local sandstorm activity but might be provoked by other effects. Especially in the case of Missour where no surface damage could be observed via microscope analysis, the decrease in $\rho_{\lambda, \varphi}$ might be provoked by humidity, diurnal and annual fine particulates [60, 3, 61] In the following the results from the field exposure in Kuwait are shown. Because of the dimension of the sample $\left(20 \mathrm{x} 40 \mathrm{~cm}^{2}\right)$ it was possible to investigate the spatial $\rho_{\lambda, \varphi}$ loss distribution on the sample. Fig. 11 shows the measured $\rho_{\lambda, \varphi}$ values coming from 4 x 38 measurement points cause of the smaller dimension in this direction and the lower $\rho_{\lambda, \varphi}$ resolution.

The Acetube was used for artificial erosion experiments on glass reflectors for CSP applications with the natural soil samples at different wind velocities. 410 

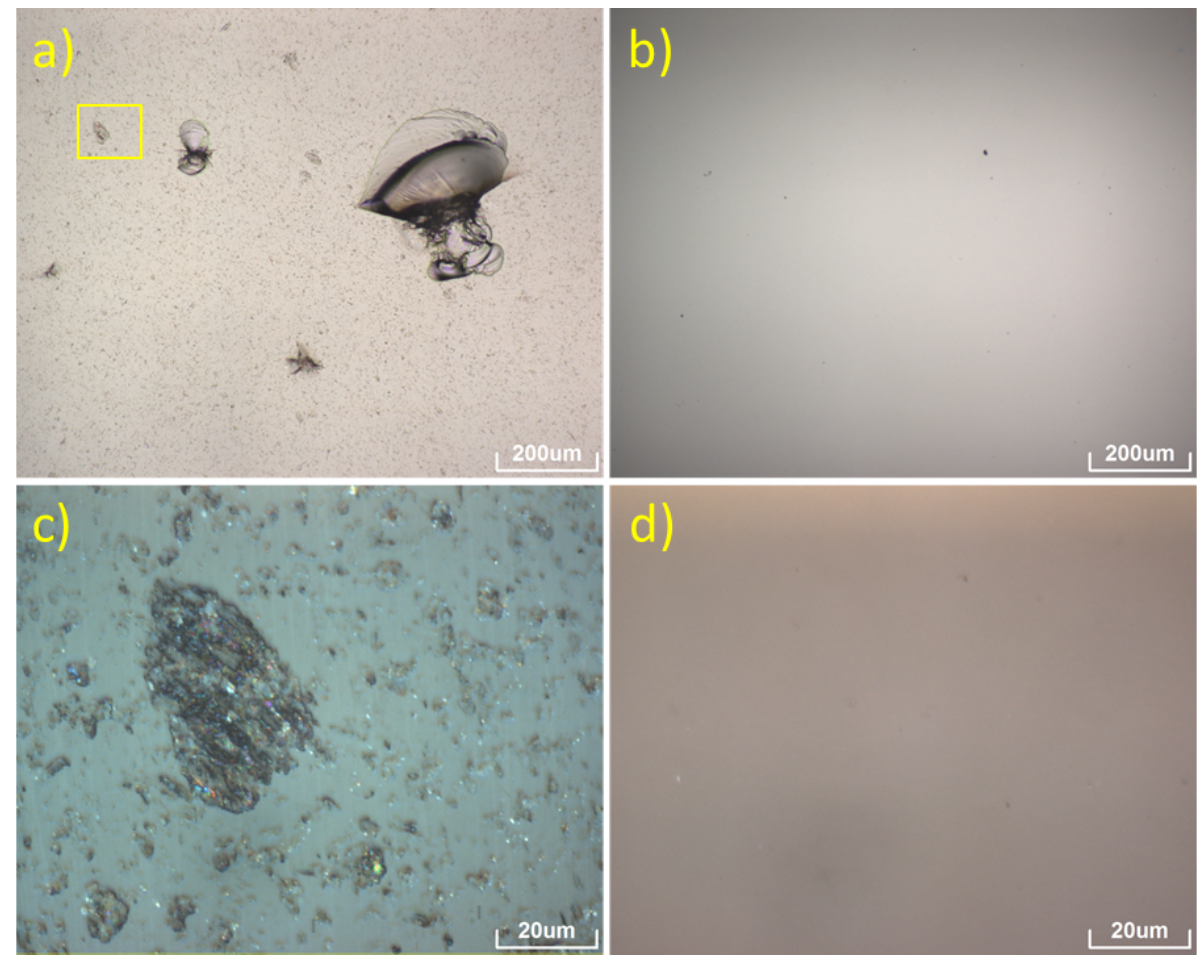

Fig. 10: Microscope picture of the glass surface of a solar reflector exposed for 26 months (June 2013 to August 2015) in Zagora (a) and (c) with (c) representing the magnification of the yellow rectangle in (a) and in Missour (b) and (d). 

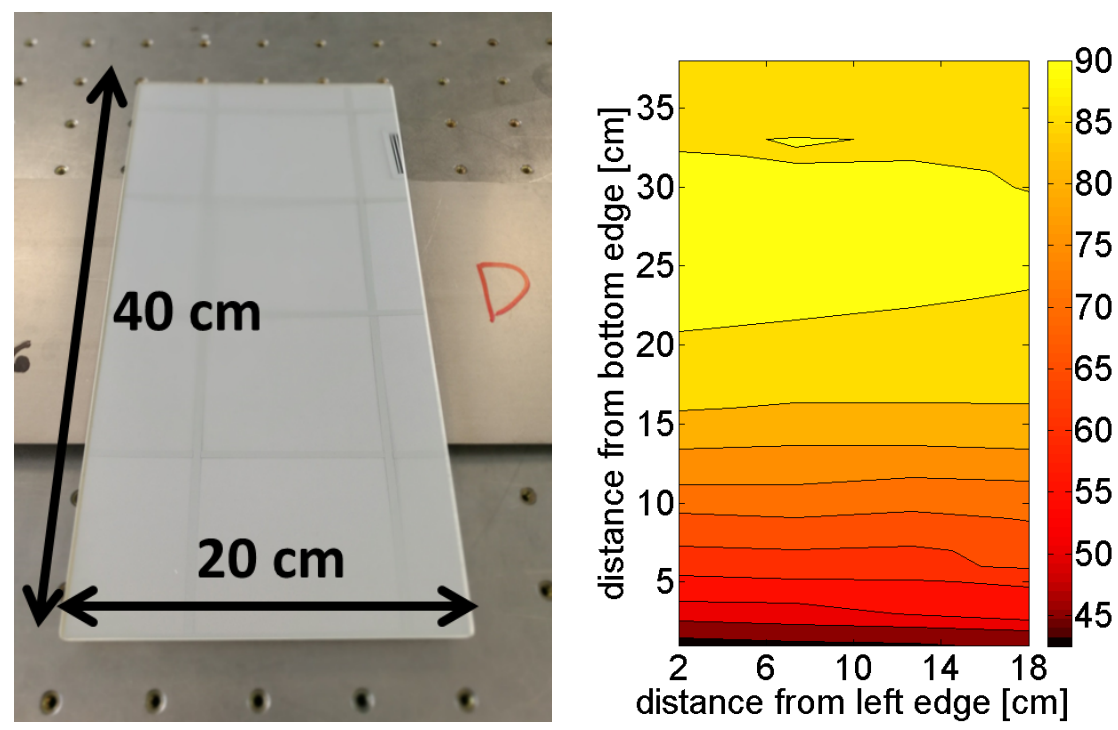

Fig. 11: Mirror sample which was exposed in Kuwait for nine months (from November 2015 to July 2016) with its spatial dimensions and the $\rho_{\lambda, \varphi}$ analysis coming from 4 x 38 measurement spots. Yellow colors represent comparably high $\rho_{\lambda, \varphi}$ values while red colors represent eroded regions on the mirror.

specular reflectance $\rho_{\lambda, \varphi}$ was measured before and after the experiment and the resulting difference is plotted as reflectance loss $\rho_{s, l o s s}$ in Fig. 12 as a function of the wind velocity $u$. For all $u, \rho_{s, l o s s}$ is higher when soil from Zagora is used instead of the soil from Missour. On the one hand this can be explained by the

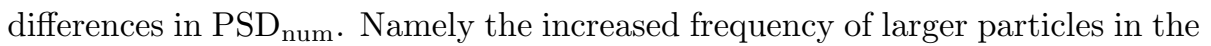
Zagora soil (even though only particles with diameters smaller than $150 \mu \mathrm{m}$ were used). As mentioned in section 1.1 the particle diameter contributes significantly to the erosion rate. On the other hand the higher reflectance loss provoked by soil samples of Zagora can be explained by the increased percentage of quartz in the Zagora soil which is around 5.6 times higher than in the soil from Missour. At low testing velocities and particle diameters it is reasonable to assume that only the hard quartz particles are able to penetrate into the glass and cause inelastic impacts.

It further becomes apparent that $\rho_{\lambda, \varphi}$ decreases faster with increasing $u$ for the 


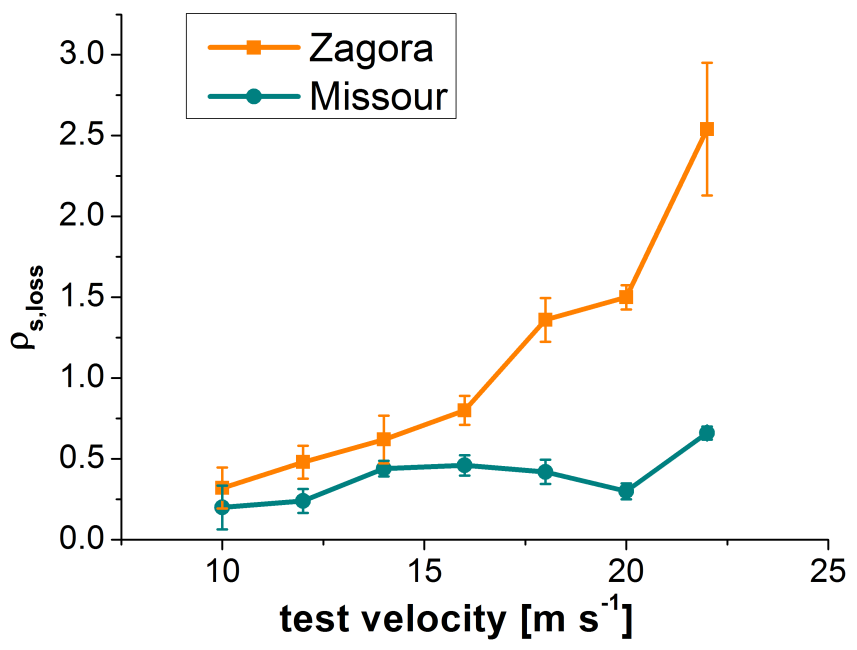

Fig. 12: $\rho_{s, \text { loss }}$ at different testing velocities in the Acetube for erodent materials from Zagora and Missour soil where particles $>150 \mu \mathrm{m}$ have been removed previously. Test mass density $m_{A}$ for each test run was $0.19 \mathrm{~g} \mathrm{~cm}^{-2}$. Test duration was around 20 minutes.

Zagora soil. In other words, the velocity exponent $l$ (from Wada [13]) changes to a higher value at a certain $u$. One explanation could be a threshold limit of the erosion rate, that is already reached in the case of Zagora soil in the investigated velocity range maybe caused by the aforementioned higher content of larger particles. 


\section{Conclusion}

In this study, the potential risk of erosive degradation on solar energy materials by sandstorms has been described theoretically and a practical assessment of relevant sites has been performed. Outdoor exposed samples at two sites already showed significant erosion defects. Samples exposed in Kuwait lost up to $53.5 \%$ of specular reflectance (after nine months at around $0.4 \mathrm{~m}$ above ground), while samples in Zagora and Missour lost $5.9 \pm 0.4 \%$ and $0.8 \pm 0.1 \%$ respectively (both after 25 months at around $1.2 \mathrm{~m}$ above ground). Regarding the meteorological site characterization, at first the relevant parameters that lead to critical sand movement on reflector surfaces have been pointed out. It has been shown in literature, that there is a minimum for $u_{\tau}^{*}$ which leads to particularly efficient saltation processes at particle diameters of around $100 \mu \mathrm{m}$. Smaller particles, responsible for soiling are mainly transported over longer distances in the suspension mode, but they barely take part in the erosion process of glass surfaces. The $\mathrm{PSD}_{\text {num }}$ analysis reveals the presence of a second mode in the critical size ${ }_{445}$ region for the soil samples collected in Zagora while this is not the case for the soil from Missour. Such bimodal $\mathrm{PSD}_{\text {num }}$ is ascribed a promotion of particle saltation. Particle shape analysis has been performed for both sites and no significant difference could be detected. The evaluation of the meteorological data sowed $r h$ values for Zagora which was in average $25.3 \%$ in comparison to $47.7 \%$ in Missour. Soil humidity which can be linked to $r h$ is an important input parameter for saltation models and it is known that dry soils promote the onset of saltation significantly. Additionally a high clay content in the soil favors water adsorption. The gravimetrical contribution of fine silt and clay particles in Missour is 25 times higher than in Zagora and lies around 7.4\%, while it is only $0.3 \%$ in Zagora. The general analysis of the relative frequency of measured wind velocities did not show significant differences between the two sites, but if only events with $r h<10 \%$ were taken into account, a probability for extreme wind events which is four times higher in Zagora than in Missour could be demonstrated. In summary, the conditions as found in Zagora favor 
Once a site is believed to eventually allow particle saltation, an estimation of its damage potential can be obtained by accelerated aging experiments with the respective soil from the site. Particles of the same size range from Zagora and Missour have been used in an artificial accelerated erosion setup at different test velocities. $\rho_{\lambda, \varphi}$ was determined to quantify degradation of glass mirror samples after the accelerated erosion treatment and an increasing optical performance loss with impact velocity could be determined. This is in agreement with theory, since the impact energy of the particles rises with the square of velocity. Furthermore, an increased erosion efficiency of the erodent material from Zagora From theoretical considerations it could be concluded that a bigger $d$ and a larger erodent particel hardness $H_{p}$ leads to a higher erosion rate. The erodent material extracted from the soil of Zagora exhibits a PSD $_{\text {num }}$ where bigger particles are present more frequently than in Missour and further contains around

Erosion effects due to impacts of windblown particles can significantly affect the optical performance of solar power materials. A CSP plant with its reflectors exposed to similar annual erosion damage as it has been measured in Zagora would not be competitive. Due to the optical working principles of the respective technologies the same can be stated for a PV plant even though to a less pronounced extent since flat panel PV technology not only exploits direct solar radiation [2. Light scattered on defects of the glass surface is still available for the photovoltaic energy conversion process but will not strike the receiver for concentrating technologies 62. It should be of high interest for plant designers to estimate the risk of erosive sandstorm events for the selected outdoor sites. Complete modeling of saltation processes under natural conditions is difficult since the solutions require bulky parameters whose acquisition can be complex. The most reliable conclusion about the actual erosion risk due to sandstorms 490 
can be a time consuming task. This study therefore points out some easily measurable parameters that could serve as indicators for the potential erosion risk of optical components for solar energy plants. Care has to be taken if:

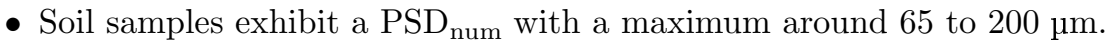

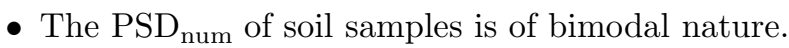

- The terrain exhibits no surface features and is basically a vast plain without vegetation or obstacles serving as wind barrier. Wind velocities are higher than $10 \mathrm{~m} \mathrm{~s}^{-1}$ (measured at $10 \mathrm{~m}$ above ground).

- Low relative humidity and high wind velocities are present at the same time.

- High TSP concentrations (> $1000 \mu \mathrm{g} \mathrm{m}^{-3}$ ) are measured.

- A low clay content in the soil is present which will lead to less efficient water adsorption which lowers the soil moisture and in the end favors saltation.

505

- A high quartz content in the soil is present which will lead to intensive erosion effects if particles reach saltation mode.

Certainly, the presence of only one or two of the above mentioned aspects could be balanced by the absence of the remaining aspects but care should be taken to further investigate the chosen site for a solar power plant and to select adequate optical materials [6] if a few of the points could be verified. 


\section{Outlook}

The $\rho_{\lambda, \varphi}$ losses that have been measured within this study should be understood as worst-case scenario effects. Under realistic power plant conditions they should only occur on the outermost panels/mirrors facing the predominant wind direction. The inner part of a solar power plants should be relatively safe regarding the wind erosion risk because they are shielded by the outer ones. If a site has been detected to be of high erosion risk there still remains the possibility to make use of sand movement prevention technology. Especially in the Asian regions a lot of possible countermeasures like wind fences, vegetation or artificial gravel surfaces as it has been described e.g. by Cheng and Xue or Liu et al. 63, 64 have been tested. These effects should be taken into account in further projects to assess the effect of sand storms in the entire field, e.g. by making use of CFD computation tools. 


\section{Acknowledgement}

${ }_{525}$ This project has received funding from the European Union's Horizon 2020 innovation programme under grant agreement Nr. 686008, project RAISELIFE.

The authors want to thank Tomás Jesús Reche Navarro (DLR) and Johannes Wette (DLR) and Luis Millan Monte (TSK) for their support. 


\section{References}

530 [1] J. A. Ruiz-Arias, C. A. Gueymard, F. J. Santos-Alamillos, D. PozoVázquez, Worldwide impact of aerosols time scale on the predicted longterm concentrating solar power potential, Scientific reports 6 (2016) 30546.

[2] T. Sarver, A. Al-Qaraghuli, L. L. Kazmerski, A comprehensive review of the impact of dust on the use of solar energy: History, investigations, results, literature, and mitigation approaches, Renewable and Sustainable Energy Reviews 22 (2013) 698-733.

[3] M. R. Maghami, H. Hizam, C. Gomes, M. A. Radzi, M. I. Rezadad, S. Hajighorbani, Power loss due to soiling on solar panel: A review, Renewable and Sustainable Energy Reviews 59 (2016) 1307-1316.

[4] N. Hanrieder, Determination of atmospheric extinction for solar tower plants, Ph.D. thesis, RWTH Aachen (2016).

[5] M. Schiller, T. Höing, Leistungsfähige Spiegel für solarthermische Kraftwerke, Vakuum in Forschung und Praxis 24 (2) (2012) 14-17.

[6] M. Humood, A. Beheshti, J. Meyer, A. A. Polycarpou, Normal impact of sand particles with solar panel glass surfaces, Tribology International 102 (2016) 237-248.

[7] F. Wiesinger, F. Sutter, A. Fernández-García, J. Reinhold, R. Pitz-Paal, Sand erosion on solar reflectors: Accelerated simulation and comparison with field data, Solar Energy Materials and Solar Cells 145 (2016) 303313.

[8] H. Houmy, A. Khaldoun, H. Ennaceri, A. Ghennioui, A. Ennaoui, Towards a simple sand and dust abrasion and soiling prediction on solar components, IRSEC, Marrakech (2016).

[9] C. Sansom, P. Comley, P. King, H. Almond, C. Atkinson, E. Endaya, Predicting the Effects of Sand Erosion on Collector Surfaces in CSP Plants, Energy Procedia 69 (2015) 198-207. 
[10] M. Karim, S. Naamane, C. Delord, A. Bennouna, Laboratory simulation of the surface erosion of solar glass mirrors, Solar Energy 118 (2015) 520-532.

[11] A. Al Shehri, B. Parrott, P. Carrasco, H. Al Saiari, I. Taie, Accelerated testbed for studying the wear, optical and electrical characteristics of dry cleaned pv solar panels, Solar Energy 146 (2017) 8-19.

[12] I. Hutchings, Transitions, threshold effects and erosion maps, in: Key Engineering Materials, Vol. 71, Trans Tech Publ, 1992, pp. 75-92.

[13] S. Wada, Effects of hardness and fracture toughness of target materials and impact particles on erosion of ceramic materials, in: Key Engineering Materials, Vol. 71, Trans Tech Publ, 1992, pp. 51-74.

[14] Z. Feng, A. Ball, The erosion of four materials using seven erodents towards an understanding, Wear 233-235 (1999) 674-684.

[15] A. Fernández-García, E. Zarza, L. Valenzuela, M. Pérez, Parabolic-trough solar collectors and their applications, Renewable and Sustainable Energy Reviews 14 (7) (2010) 1695-1721.

[16] J. Wette, F. Sutter, A. Fernndez-Garca, Correlating outdoor exposure with accelerated aging tests for aluminum solar reflectors, AIP Conference Proceedings 1734 (1) (2016) 090003.

575 [17] N. Subramaniam, M. Al-Sudairawi, A. Al-Dousari, N. Al-Dousari, Probability distribution and extreme value analysis of total suspended particulate matter in Kuwait, Arabian Journal of Geosciences (2015) 1-16.

[18] F. Wiesinger, F. Sutter, Report on erosion of construction materials, 2016, Technical report, STAGE-STE.

580 [19] H. Wensink, M. C. Elwenspoek, A closer look at the ductilebrittle transition in solid particle erosion, Wear 253 (910) (2002) 1035-1043. 
[20] G. L. Sheldon, I. Finnie, On the ductile behavior of nominally brittle materials during erosive cutting, Journal of Engineering for Industry 88 (4) (1966) 387-392.

[27] Y. Shao, M. Raupach, P. Findlater, Effect of saltation bombardment on the entrainment of dust by wind, Journal of Geophysical Research 98 (D7) (1993) 12719-12726.

[28] P. J. Slikkerveer, M. Verspui, E. Skerka, Erosion and damage by hard spher605 ical particles on glass, Journal of the American Ceramic Society 82 (11) (1999) 3173-3178.

[29] R. P. Sharp, Wind-Driven Sand in Coachella Valley, California, Geological Society of America Bulletin 75 (9) (1964) 785-804. 
[30] J. P. Thornton, The effect of sandstorms on pv arrays and components, in: Proceedings of the National Solar Energy Conference, Cocao Beach, 1992.

[31] C. Sansom, H. Almond, P. King, E. Endaya, S. Bouaichaoui, Airborne sand and dust soiling of solar collecting mirrors, AIP Conference Proceedings 1850 (1) (2017) 130011.

[32] J.-j. Cheng, F.-q. Jiang, C.-x. Xue, G.-w. Xin, K.-c. Li, Y.-h. Yang, Characteristics of the disastrous wind-sand environment along railways in the gobi area of xinjiang, china, Atmospheric Environment 102 (0) (2015) 344-354.

[33] K. Darmenova, I. N. Sokolik, Y. Shao, B. Marticorena, G. Bergametti, Development of a physically based dust emission module within the weather research and forecasting (wrf) model: Assessment of dust emission parameterizations and input parameters for source regions in central and east asia, Journal of Geophysical Research: Atmospheres 114 (D14).

[34] W. Nickling, The initiation of particle movement by wind, Sedimentology 35 (3) (1988) 499-511.

[35] R. Greeley, J. D. Iversen, Wind as a geological process: on Earth, Mars, Venus and Titan, Vol. 4, CUP Archive, 1987.

[36] M. Mikami, Y. Yamada, M. Ishizuka, T. Ishimaru, W. Gao, F. Zeng, Measurement of saltation process over gobi and sand dunes in the taklimakan desert, china, with newly developed sand particle counter, Journal of Geophysical Research: Atmospheres (19842012) 110 (D18).

${ }_{630}^{63}$ [37] T. von Kármán, Mechanical similitude and turbulence (1931).

[38] G. Williams, Some aspects of the eolian saltation load, Sedimentology 3 (4) (1964) 257-287.

[39] E. J. Farrell, D. J. Sherman, J. T. Ellis, B. Li, Vertical distribution of grain size for wind blown sand, Aeolian Research 7 (2012) 51-61. 
[40] B. B. Willetts, M. A. Rice, S. E. Swaine, Shape effects in aeolian grain transport, Sedimentology 29 (3) (1982) 409-417.

[41] B. Willetts, Transport by wind of granular materials of different grain shapes and densities, Sedimentology 30 (5) (1983) 669-679.

[42] C. McKenna-Neuman, W. G. Nickling, A theoretical and wind tunnel investigation of the effect of capillary water on the entrainment of sediment by wind, Canadian Journal of Soil Science 69 (1) (1989) 79-96.

[43] S. Ravi, P. D'Odorico, A field-scale analysis of the dependence of wind erosion threshold velocity on air humidity, Geophysical Research Letters $32(21)$.

[44] F. Fécan, B. Marticorena, G. Bergametti, Parametrization of the increase of the aeolian erosion threshold wind friction velocity due to soil moisture for arid and semi-arid areas, Annales Geophysicae 17 (1) (1998) 149-157.

[45] W. M. Cornelis, D. Gabriels, R. Hartmann, A parameterisation for the threshold shear velocity to initiate deflation of dry and wet sediment, Geomorphology 59 (1) (2004) 43-51.

[46] A. Selah, D. W. Fryrear, Threshold wind velocities of wet soils as affected by wind blown sand, Soil Science 160 (4) (1995) 304-309.

[47] D. Schüler, S. Wilbert, N. Geuder, R. Affolter, F. Wolfertstetter, C. Prahl, M. Rger, M. Schroedter-Homscheidt, G. Abdellatif, A. A. Guizani, M. Balghouthi, A. Khalil, A. Mezrhab, A. Al-Salaymeh, N. Yassaa, F. Chellali, D. Draou, P. Blanc, J. Dubranna, O. M. K. Sabry, The enermena meteorological network solar radiation measurements in the mena region, AIP Conference Proceedings 1734 (1) (2016) 150008.

[48] enerMENA, http://www.dlr.de/sf/desktopdefault.aspx/tabid-7235/ (Accessed: 2017-06-29). 
[49] B. Weinzierl, A. Petzold, M. Esselborn, M. Wirth, K. Rasp, K. Kandler, L. Schütz, P. Koepke, M. Fiebig, Airborne measurements of dust layer properties, particle size distribution and mixing state of saharan dust during samum 2006, Tellus B 61 (1) (2009) 96-117.

[50] F. Wiesinger, F. Sutter, F. Wolfertstetter, N. Hanrieder, J. Wette, A. Fernández-García, R. Pitz-Paal, Sandstorm erosion simulation on solar mirrors and comparison with field data, AIP Conference Proceedings 1850 (1) (2017) 130014.

[51] S. Reichenspurner, Particle erosion on solar mirrors: Construction and first experimental stage of an open loop wind tunnel, B.Sc. thesis, University of applied sciences Kempten (2016).

[52] DIN 52348, Prüfung von Glas und Kunststoff, in: Verschleißprüfung - Sandrieselverfahren, Deutsches Institut für Normung, 1985.

[53] D. Kaskaoutis, A. Rashki, E. Houssos, A. Mofidi, D. Goto, A. Bartzokas, P. Francois, M. Legrand, Meteorological aspects associated with dust storms in the sistan region, southeastern iran, Climate Dynamics (2014) 118.

[54] N. Boddupalli, G. Singh, L. Chandra, B. Bandyopadhyay, Dealing with dust some challenges and solutions for enabling solar energy in desert regions, Solar Energy 150 (2017) 166-176.

[55] M. V. Sivakumar, N. Ndiang'Ui, Climate and land degradation, Springer Science and Business Media, 2007.

[56] W. Chepil, N. Woodruff, Sedimentary characteristics of dust storms; Part II, Visibility and dust concentration, American Journal of Science 255 (2) (1957) 104-114.

[57] K. Kandler, L. Schütz, C. Deutscher, M. Ebert, H. Hofmann, S. Jäckel, R. Jaenicke, P. Knippertz, K. Lieke, A. Massling, Size distribution, mass 
concentration, chemical and mineralogical composition and derived optical parameters of the boundary layer aerosol at tinfou, morocco, during samum 2006, Tellus B 61 (1) (2009) 32-50.

[58] D. L. Whitney, A. K. Fayon, M. E. Broz, R. F. Cook, Exploring the relationship of scratch resistance, hardness, and other physical properties of minerals using mohs scale minerals, Journal of Geoscience Education 55 (1) (2007) 56-61.

[59] W. Krumbein, L. Sloss, Properties of sedimentary rocks, Stratigraphy and Sedimentation (1963) 106-113.

[60] A. García-Segura, A. Fernández-García, M. J. Ariza, F. Sutter, L. Valenzuela, Durability studies of solar reflectors: A review, Renewable and Sustainable Energy Reviews 62 (2016) 453-467.

[61] F. Sutter, A. Fernández-García, P. Heller, K. Anderson, G. Wilson, M. Schmcker, P. Marvig, Durability testing of silvered-glass mirrors, Energy Procedia 69 (2015) 1568-1577.

[62] M. Karim, S. Naamane, I. E. A. E. Hassani, C. Delord, S. Belcadi, P. Tochon, A. Bennouna, Towards the prediction of csp mirrors wear: Methodology of analysis of influencing parameters on the mirrors surface degradation: Application in two different sites in morocco, Solar Energy 108 (2014) $41-50$.

[63] J.-j. Cheng, C.-x. Xue, The sand-damageprevention engineering system for the railway in the desert region of the qinghai-tibet plateau, Journal of Wind Engineering and Industrial Aerodynamics 125 (2014) 30-37.

[64] B. Liu, W. Zhang, J. Qu, K. Zhang, Q. Han, Controlling windblown sand problems by an artificial gravel surface: A case study over the gobi surface of the mogao grottoes, Geomorphology 134 (3) (2011) 461-469. 